\title{
Gamma Oscillations in the Rat Ventral Striatum Originate in the Piriform Cortex
}

\author{
ㄴ)James E. Carmichael, Jimmie M. Gmaz, and $\oplus^{M a t t h i j s ~ A . A . ~ v a n ~ d e r ~ M e e r ~}$ \\ Department of Psychological and Brain Sciences, Dartmouth College, Hanover, New Hampshire 03755
}

Local field potentials (LFPs) recorded from the human and rodent ventral striatum (vStr) exhibit prominent, behaviorally relevant gamma-band oscillations. These oscillations are related to local spiking activity and transiently synchronize with anatomically related areas, suggesting a possible role in organizing vStr activity. However, the origin of vStr gamma is unknown. We recorded vStr gamma oscillations across a $1.4 \mathrm{~mm}^{2}$ grid spanned by 64 recording electrodes as male rats rested and foraged for rewards, revealing a highly consistent power gradient originating in the adjacent piriform cortex. Phase differences across the vStr were consistently small $\left(<15^{\circ}\right)$ and current source density analysis further confirmed the absence of local sink-source pairs in the vStr. Reversible occlusions of the ipsilateral (but not contralateral) nostril, known to abolish gamma oscillations in the piriform cortex, strongly reduced vStr gamma power and the occurrence of transient gamma-band events. These results imply that local circuitry is not a major contributor to gamma oscillations in the vStr LFP and that piriform cortex is an important driver of gamma-band oscillations in the vStr and associated limbic areas.

Key words: accumbens; gamma oscillations; local field potential; phase locking; piriform cortex; synchrony

\section{Significance Statement}

The ventral striatum (vStr) is an area of anatomical convergence in circuits underlying motivated behavior, but it remains unclear how its inputs from different sources interact. A major proposal about how neural circuits may switch dynamically between convergent inputs is through temporal organization reflected in local field potential (LFP) oscillations. Our results show that, in the rat, the mechanisms controlling gamma-band oscillations in the vStr LFP are primarily located in the in the adjacent piriform cortex rather than in the vStr itself, providing a novel interpretation of previous rodent work on gamma oscillations in the vStr and related circuits and an important consideration for future work seeking to use oscillations in these areas as biomarkers for behavioral and neurological disorders.

\section{Introduction}

The ventral striatum (vStr) is an anatomically heterogeneous region receiving a convergence of anatomical connections from structures in the cortico-striatal-thalamic loop, as well as from the hippocampal formation and amygdala (Pennartz et al., 1994; Haber, 2009; Sesack and Grace, 2010). Prominent local field potential (LFP) oscillations can be recorded from the rodent and

Received Aug. 4, 2015; revised June 15, 2017; accepted July 8, 2017.

Author contributions: J.E.C. and M.A.A.v.d.M. designed research; J.E.C. and J.M.G. performed research; J.E.C. analyzed data; J.E.C. and M.A.A.v.d.M. wrote the paper.

This work was supported by Dartmouth College (Fellowship to J.E.C. and start-up funds to M.A.A.v.d.M.) and the Natural Sciences and Engineering Research Council (NSERC) of Canada (Discovery Grant to M.A.A.v.d.M. and Canada Graduate Scholarship to J.M.G.). We thank Nancy Gibson, Martin Ryan, and Jean Flanagan for animal care; Claire Cheetham for suggesting the naris occlusion technique; Youki Tanaka for reagents; and Min-Ching Kuo and Alyssa Carey for technical assistance.

The authors declare no competing financial interests.

Correspondence should be addressed to Matthiijs A.A. van der Meer, Department of Psychological and Brain Sciences, Dartmouth College, 3 Maynard St., Hanover, NH 03755. E-mail: mvdm@dartmouth.edu.

DOI:10.1523/JNEUROSCI.2944-15.2017

Copyright $\odot 2017$ the authors $\quad 0270-6474 / 17 / 377962-13 \$ 15.00 / 0$ human vStr, spanning a broad range of frequencies that include delta, theta, beta, multiple gamma bands, and high-frequency oscillations (Berke et al., 2004; Hunt et al., 2010; van der Meer and Redish, 2009; Axmacher et al., 2010; Dürschmid et al., 2013) and display phase-amplitude coupling (humans: Cohen et al., 2009a, rodents: Donnelly et al., 2014; Malhotra et al., 2015). A particularly salient feature of the vStr LFP is the presence of prominent gamma-band oscillations, which include distinct low-gamma $(\sim 45-65 \mathrm{~Hz})$ and high-gamma $(\sim 70-90 \mathrm{~Hz})$ components (van der Meer et al., 2010).

Several studies have found correlations between the occurrence of these low- and high-gamma oscillations and aspects of behavior such as reward approach and/or receipt (Berke, 2009; van der Meer and Redish, 2009; Kalenscher et al., 2010, but see Malhotra et al., 2015), reward expectation and prediction errors (Cohen et al., 2009a; Axmacher et al., 2010), drug-related conditioned place preference (Dejean et al., 2017), and impulsive actions (Donnelly et al., 2014). vStr gamma oscillations are also affected by manipulations of the dopamine and cannabinoid sys- 
tems (Berke, 2009; Lemaire et al., 2012; Morra et al., 2012). Importantly, the spiking of vStr neurons is related to these gamma oscillations, with putative fast-spiking interneurons (FSIs) displaying a particularly striking pattern: partially distinct populations appear to phase lock to low- and high-gamma, respectively Berke, 2004; van der Meer and Redish, 2009; Dejean et al., 2017. Medium spiny neurons, which make up the vast majority of vStr neurons, tend to show weaker but nonetheless statistically significant phase locking (Kalenscher et al., 2010; Howe et al., 2011) and ensemble spiking activity can predict which gamma-band oscillation is present in the LFP (Catanese et al., 2016).

A conservative interpretation of the above body of work is to view gamma oscillations in the vStr LFP as a signal containing a certain amount of information about the state of the local network; that is, as a practically useful readout. However, in several brain structures, there is evidence that the effectiveness of an incoming stimulus can depend on the phase of local gamma oscillations (Cardin et al., 2009; Sohal et al., 2009). Although such state dependence has not yet been shown in the vStr, the findings reviewed so far suggest the possibility that the mechanisms generating vStr gamma contribute to dynamic gain control, as in the "communication through coherence" proposals (Akam and Kullmann, 2010; Womelsdorf et al., 2014; Fries, 2015). This idea is conceptually attractive given the anatomical convergence of multiple inputs onto the vStr (O'Donnell and Grace, 1995; Gruber et al., 2009; Harris and Gordon, 2015); indeed, gamma oscillations in the vStr LFP are often coherent with gamma-band LFP signals in anatomically related areas, with prefrontal cortical areas being the best-studied example (rodent: Berke, 2009; McCracken and Grace, 2009; Dejean et al., 2013; Catanese et al., 2016; Amadei et al., 2017, human: Cohen et al., 2009b).

For both the "readout" or "gain control mechanism" views of vStr gamma oscillations, it is important to establish how this signal is generated; a crucial first step is to localize their source(s), which have so far remained unclear. Some studies emphasize the similarity of vStr gamma oscillations with those recorded in the adjacent piriform cortex (Berke, 2009), whereas other studies report local heterogeneities that appear to be inconsistent with volume conduction (Kalenscher et al., 2010; Morra et al., 2012) or focus on cell-intrinsic contributions (Taverna et al., 2007). Resolving this issue would help to determine whether local vStr circuitry may implement a "switchboard" through a communicationthrough-coherence type mechanism (Fries, 2005; Gruber et al., 2009; Akam and Kullmann, 2010) and would enable a productive dialog between rodent and human studies in which vStr LFPs may have behavioral and clinical relevance (Sturm et al., 2003; McCracken and Grace, 2009; Dejean et al., 2013; Doucette et al., 2015).

Therefore, to determine the origin of gamma oscillations in the LFP of the rat vStr, we recorded from sites across the vStr using a high-density electrode array and inactivated the piriform cortex using reversible naris (nostril) occlusions known to abolish piriform gamma (Zibrowski and Vanderwolf, 1997).

\section{Materials and Methods}

Overview. This study consists of two experiments: an "LFP-mapping" experiment measuring the distribution of gamma oscillations across the vStr and a "naris occlusion" experiment testing the effects of unilateral nostril closures on vStr gamma. Data in the LFP-mapping experiment were acquired as rats performed a maze-based foraging task and during off-task resting periods. Because we found no difference in the properties of gamma oscillations on and off task, data for the naris experiment were acquired during rest only. All procedures were approved by the Uni- versity of Waterloo Animal Care Committee (AUPP 11-06) and the Dartmouth College Institutional Animal Care and Use Committee (vand.ma.2).

Subjects and timeline. Seven Long-Evans male rats ( $>10$ weeks old; $>400 \mathrm{~g}$ ) were used in total: four in the LFP-mapping experiment and three in the naris occlusion experiment. For the LFP-mapping experiment, rats were pretrained on a foraging task ( $4 \mathrm{~d}$ of maze habituation), implanted with recording probes (described in detail below), and retrained on the task after recovery (minimum $4 \mathrm{~d}$ ) before acquisition of neural data began. The naris experiment included two naive rats and a final rat that had been trained previously on a maze-based, cued approach task used in Gmaz et al. (2016) (no differences were found across rats). All animals were kept on a $12 \mathrm{~h}$ light/dark cycle, with all experiments performed during the light phase.

Surgery and recording probes. Rats for the LFP-mapping experiment were implanted with 64 -channel, $50-\mu \mathrm{m}$-thick silicon probes (A8x8-10 mm-200-200-177; NeuroNexus). Probe recording sites and tetrodes were gold-plated (SIFCO 6355) to impedances between 300 and $500 \mathrm{k} \Omega$ (Nano-Z; White Matter). Probes were attached to a microdrive and implanted as in Vandecasteele et al. (2012), with the addition of a separate independently movable stainless steel wire reference electrode (goldplated to $50 \mathrm{k} \Omega$ ) implanted into the same hemisphere (AP $2.2 \mathrm{~mm}$ anterior to bregma, ML $2.0 \mathrm{~mm}$, targeting the corpus callosum overlying the vStr). The probes contained regularly spaced recording electrodes spanning $1.4 \mathrm{~mm}^{2}$ and arranged in a $8 \times 8$ grid and were implanted rotated around the vertical axis with the edges between AP 0.6-2.28, ML 1.4-2.8 (see Fig. 1C). Rats for the naris occlusion experiment were implanted with a either a custom-built four-tetrode multisite drive with one tetrode located in the vStr (AP 1.5, ML 2.0) and additional tetrodes in the orbitofrontal, prelimbic, and cingulate cortices (not analyzed here) or a custom 16-tetrode "hyperdrive" with all tetrodes in the vStr. After surgery, probes and tetrodes were moved down over the course of several days until they reached the target region (DV 6.5-8 mm).

Behavioral task. The rats in the LFP-mapping experiment were trained on a square-shaped elevated track (width $10 \mathrm{~cm}$, each edge of the square $100 \mathrm{~cm}$ long) with sucrose-dispensing reward receptacles placed at each of the four corners. Nose poking in the reward receptacles yielded $0.1,0$, 0.1 , or $0.2 \mathrm{ml}$ of $12 \%$ sucrose reward for each of the four corners, respectively; with experience (daily 40 min sessions, preceded and followed by 5-10 min of off-task recording on a terracotta planter filled with towels), animals learn to skip the nonrewarded site. Throughout behavioral training and recording on the task, rats were food restricted to $>85 \%$ of their free-feeding weight to encourage foraging behavior. The naris occlusion rats had ad libitum access to food. Before the start of the experiments described here, one of the three animals had been trained previously on a behavioral task that used the same physical setup in the same room (Gmaz et al., 2016).

Data acquisition and preprocessing. Wideband signals were acquired for the silicon probe and hyperdrive recordings using RHA2132 v0810 multiplexing headstages (Intan) and a KJE-1001/KJD-1000 amplification system (Amplipex), sampled at $20 \mathrm{kHz}$, and referenced against a single electrode in the corpus callosum above the vStr. Data for LFPmapping analysis had the DC offset removed, was decimated to $2 \mathrm{kHz}$, and filtered (1-500 Hz, 10th order Butterworth, filtfilt.m). To extract spikes from the continuously sampled Amplipex data, the data were filtered (600-9000 Hz), thresholded, and peak aligned (UltraMegaSort2k; Hill et al., 2011). Putative single neurons were manually sorted using MClust 3.5 (A.D. Redish, University of Minnesota, St. Paul, MN). Electrode sites with irregular impedance values $(>900 \mathrm{k} \Omega)$, intermittent signals, or known defective sites (B-stock probes) were excluded from analysis (black pixels in Figs. 2-5). Recordings for the naive multisite 4-tetrode drive rats used a Digital Lynx data acquisition system with an HS-18MM preamplifier (Neuralynx), sampling LFP data at $2 \mathrm{kHz}$ with a $1-475 \mathrm{~Hz}$ band-pass filter.

Naris occlusion. Reversible naris closures (nose plugs) were constructed from PE90/100 tubing (BD Intramedic) by tying a human hair and a suture in a double knot, threading it through the side of the tubing, and gluing it to the inside of the tube such that it protruded $\sim 8 \mathrm{~mm}$ beyond the tubing, facilitating subsequent removal (Kucharski and Hall, 
1987; Cummings et al., 1997). Nose plugs were coated with Vaseline and inserted (or removed) while the rat was briefly under isoflurane anesthesia ( $\leq 2 \mathrm{~min}$ from the time of induction). The effectiveness of this procedure in blocking air flow through the occluded nostril was verified by visual inspection: any remaining airflow tended to move the Vaseline. Daily recording sessions consisted of four off-task segments (see Fig. 7A): a nonocclusion baseline ("pre"), ipsilateral and contralateral naris occlusions (order counterbalanced across sessions), and another nonocclusion baseline ("post"). Each segment was separated by $45 \mathrm{~min}$ from the preceding one to minimize any effects of the isoflurane anesthesia.

Session inclusion criteria. For each subject in the LFP-mapping experiment, data from three consecutive daily recording sessions were analyzed with the recording probe at the same depth across days. These sessions were chosen such that the probe was at the same depth across sessions and the animal had reached the performance criterion on the task (skipping the nonrewarded port on $80 \%$ of the trials); if they did not (two of four rats), then the final three sessions at a consistent depth were used. For one subject in the LFP-mapping experiment, only two sessions were included due to a faulty recording tether. For the naris occlusion experiment, $4 \mathrm{~d}$ of data were recorded and analyzed ( 2 recording days, followed by $1 \mathrm{~d}$ of no recording, and $2 \mathrm{~d}$ more).

Data analysis overview. All analyses were performed using MATLAB 2014a (The MathWorks) and can be reproduced using code available on our public GitHub repository (http://github.com/vandermeerlab/papers) with data files and metadata available upon request. We performed spectral analysis on the LFP data using power spectral densities (PSDs) over specific epochs within recording sessions: off-task baseline recordings before and after behavior, reward site approach (run), and reward site consumption. For the naris occlusion experiment, only off-task (rest) data were analyzed. Given that gamma oscillations in the vStr LFP tend to occur in distinct events (Masimore et al., 2005; Cohen et al., 2009b; Donnelly et al., 2014), we also performed event-based analysis, detailed below.

Gamma event detection and analysis. Gamma events were detected following the procedure in Catanese et al. (2016). First, LFP data were filtered into the bands of interest (low-gamma: 45-65 Hz; high-gamma: $70-90 \mathrm{~Hz}$ ) using a fifth-order Chebyshev filter (ripple $\mathrm{dB} 0.5$ ) with a zero-phase digital filter (MATLAB filtfilt()). The instantaneous amplitude was extracted from the filtered signal by Hilbert transform (MATLAB abs(hilbert())). For the LFP-mapping experiment, a single recording channel for gamma event detection was selected by first computing the PSD for the six most ventrolateral recording sites and using the site with the largest power averaged across frequencies in the lowgamma range $(45-65 \mathrm{~Hz})$. Large-amplitude artifacts $(>4 \mathrm{SD}$ from the mean in the unfiltered data) and chewing artifacts $(>3$ SDs from the mean amplitude envelope filtered between 200 and $500 \mathrm{~Hz}$ ) were first removed from the data. If the instantaneous amplitude surpassed the $95^{\text {th }}$ percentile across the recording session, then it was considered a candidate event. Events were excluded if they co-occurred with high voltage spindles $(>4$ SDs from the mean amplitude envelope filtered between $7-11 \mathrm{~Hz}$ ), had $<4$ cycles, or had a variance score (variance/mean of cycle peaks and troughs) $>1.5$. Finally, a threshold $(40 \mu \mathrm{V})$ was applied to the filtered amplitude to help remove false positives in the highgamma band, which tended to be lower in amplitude.

For each detected gamma event, a length-matched pseudorandom control event was extracted by identifying the period of lowest amplitude in the gamma band within a $20 \mathrm{~s}$ window before each detected gamma event. Gamma and random events were then converted into one of two formats. For gamma power analysis, events were converted to the FieldTrip format by taking $100 \mathrm{~ms}$ of data centered on detected gamma events (ft_redefinetrial(), FieldTrip toolbox; Oostenveld et al., 2011). For phase and current source density (CSD) analysis, events were converted into a three-cycle triplet by identifying the cycle with the highest amplitude and extracting it and the cycle before and after. The three extracted cycles were then interpolated to ensure that each event had an equal number of samples (214), allowing for averaging across events.

For the naris occlusion experiment, events were detected using the percentile method detailed above except that the threshold value (in microvolts) was obtained from the baseline data and then applied to the ipsilateral and contralateral recording segments; this was necessary to be able to compare the number of gamma events between conditions.

Spectral analysis. Session-wide PSDs were computed for the naris occlusion experiment using Welch's method ( $\sim 2 \mathrm{~s}$ Hanning window) on the first derivative of the data to remove the overall $1 / \mathrm{f}$ trend (MATLAB pwelch(diff(data))). Event-based gamma power was computed using the FieldTrip toolbox (Oostenveld et al., 2011) function ft_freqanalysis ('mtmfft', Hanning window, frequency of interest (FOI) 1-500 Hz, window $5 / \mathrm{FOI}$ ) by averaging the frequencies of interest (low-gamma $45-65 \mathrm{~Hz}$; high-gamma 70-90 Hz) in the resulting PSD. Phase differences were computed relative to the most ventrolateral electrode using cross-power spectral density (MATLAB cpsd()) with a 64-sample Hamming window and $50 \%$ overlap $($ NFFT $=1024)$.

Plane fits. To quantify the consistency of any patterns in the gamma power distribution across probe recording sites, we computed a plane of best fit using least squares for the gamma power across the array during each gamma event and compared the variance explained $\left(R^{2}\right)$ to the pseudorandom nongamma events of equivalent length.

CSD analysis. CSDs were computed by taking the second spatial derivative of the band-pass-filtered data across the recording channels along the dorsomedial to ventrolateral diagonal of the recording array and multiplying it by the conductance $(0.3 \mathrm{mS} / \mathrm{mm})$. Missing channels along this diagonal were filled in by interpolation (MATLAB griddata()). Average CSDs for each rat were computed using the three-cycle triplet from each detected gamma event.

\section{Results}

\section{Experiment 1: mapping of gamma oscillations in the ventral striatum}

LFPs were recorded across the vStr of rats $(n=4)$ chronically implanted with 64-channel planar silicon probes, which covered an area of $1.4 \mathrm{~mm}^{2}$ with a regular $8 \times 8$ grid of recording sites (Fig. 1A-C). We recorded wideband neural data during behavior on an elevated maze and during off-task resting periods. As in previous reports, we found clear low- and high-gamma oscillations in the LFP (Leung and Yim, 1993; Berke et al., 2004; Howe et al., 2011; Fig. 1A) to which putative interneurons showed significant phase locking (Fig. 1D). Gamma oscillations appeared highly coherent across sites, with visual inspection suggesting systematic changes in power across the probe. To explore this effect, we isolated gamma events using a thresholding procedure on the channel with the largest average gamma-band power (see Materials and Methods); examples of detected events are shown as shaded areas in Figure $1 A$ (low-gamma: blue, high-gamma, green). We then plotted the gamma-band power across all probe sites as a heat map, illustrated for an example low-gamma event in Figure 2, $A$ and $B$. An approximately linear gradient was apparent, with the highest power at the ventrolateral pole and the lowest power at the dorsomedial pole (Fig. 2B).

As a first step toward establishing the generality of this linear gamma power gradient, we detected low-gamma $(45-65 \mathrm{~Hz})$ and high-gamma $(70-90 \mathrm{~Hz})$ events across multiple recording sessions and subjects ( 11 sessions across 4 subjects; total events detected, 6375 for low-gamma, 5227 for high-gamma; mean event rates $20.21 / \mathrm{min}$ for low-gamma, $19.93 / \mathrm{min}$ for high-gamma; mean $\pm \mathrm{SD}$. event length, $143.20 \pm 63.17 \mathrm{~ms}$ for low-gamma, $81.70 \pm 43.48 \mathrm{~ms}$ for high-gamma). Although the distribution of functional sites varied between probes, the linear gamma power gradient was consistent across subjects (Fig. 2C). Next, we investigated whether the distribution of gamma power across the vStr was affected by activity level (running on an elevated track for sucrose reward vs off-task rest) or by different behaviors during the task (approaching reward sites vs reward receipt and consumption). The observed gamma power gradient was highly consistent across all these conditions for both low- and high-gamma 

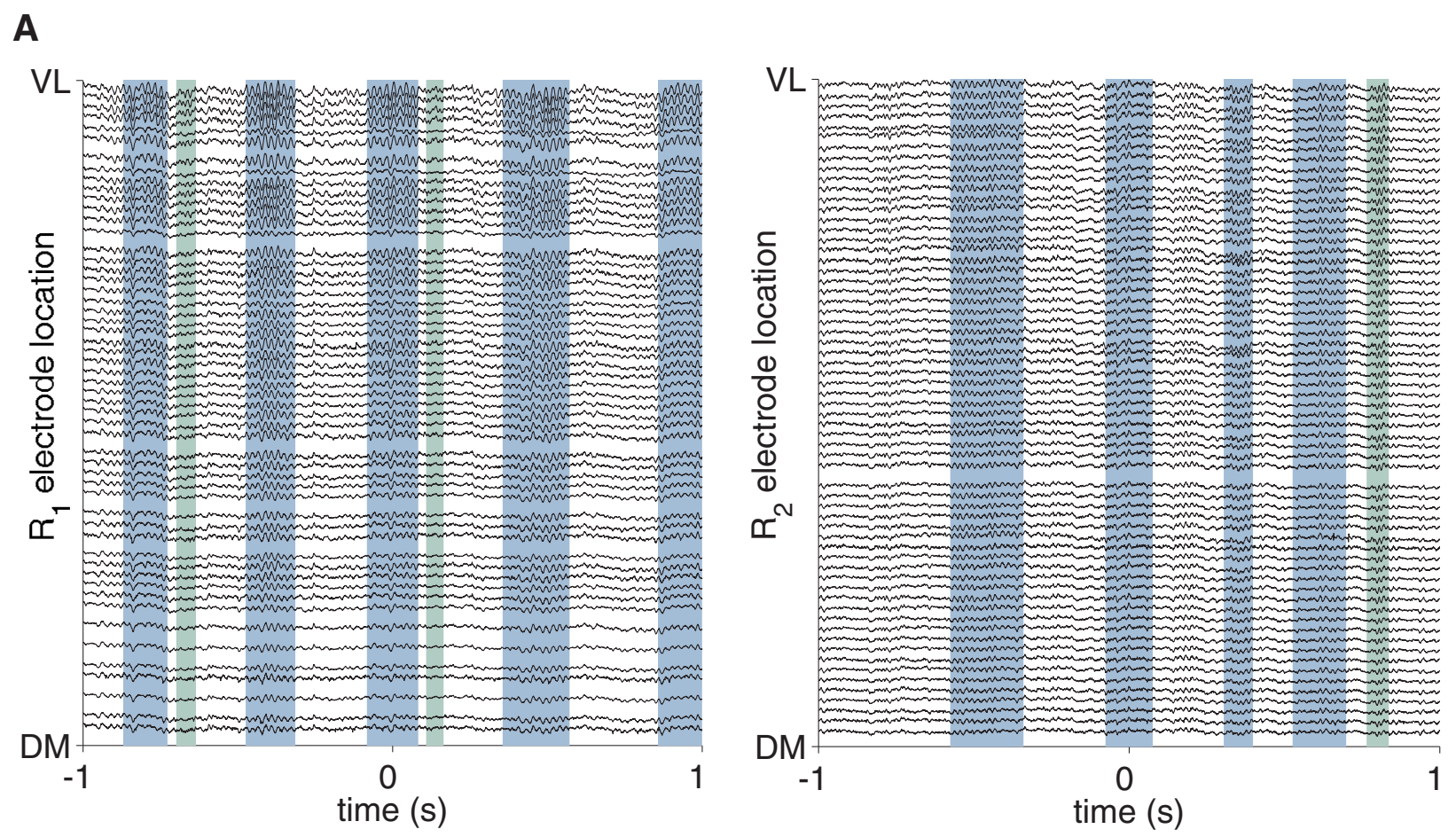

B

Posterior

(Bregma $+0.6 \mathrm{~mm})$

Anterior

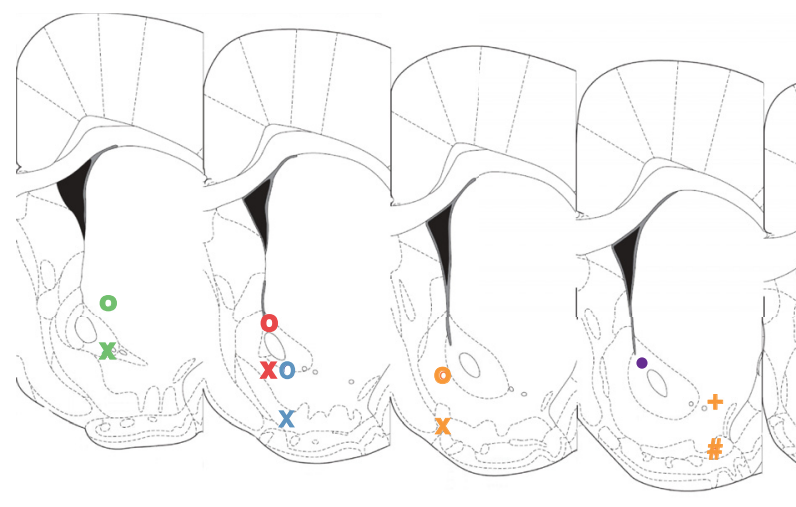

(Bregma +2.28mm)

C

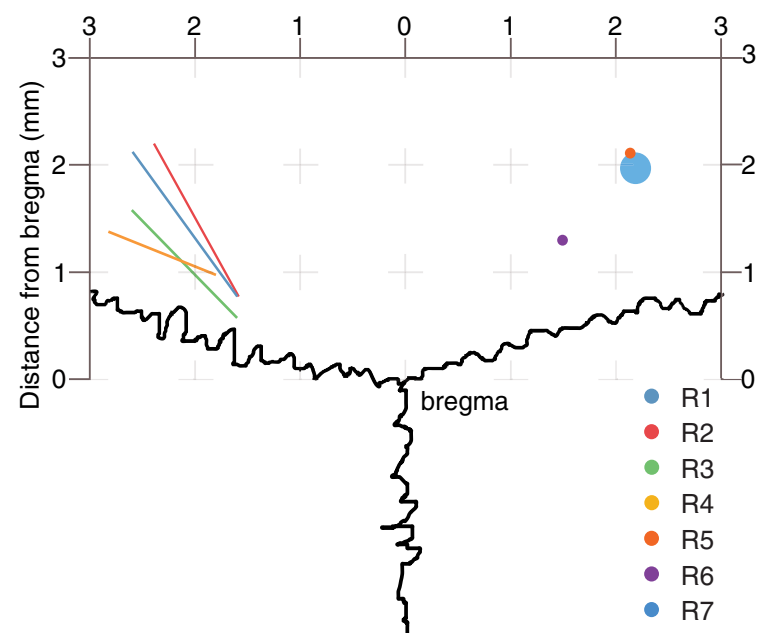

D

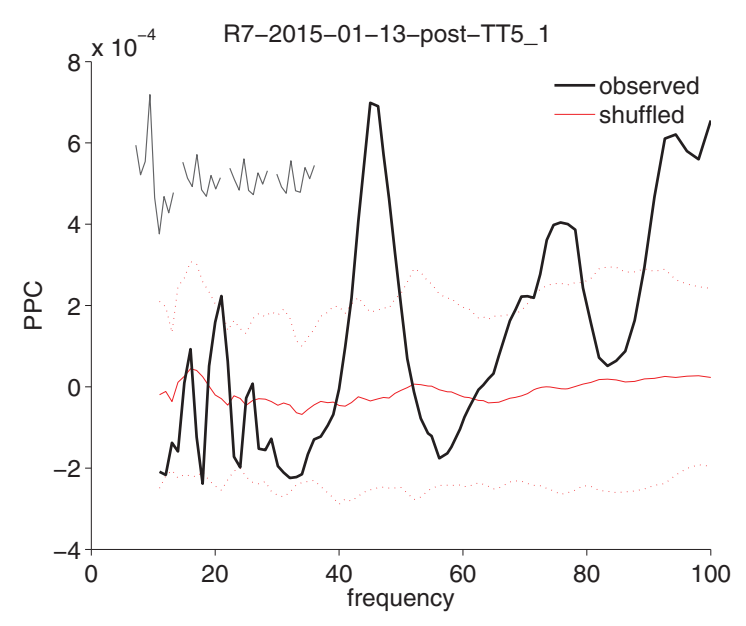

Figure 1. High-density planar silicon probe recordings across the vStr. A, Example vStr LFP traces ordered by recording site location along the ventrolateral (VL, top) to dorsomedial (DM, bottom) axis of the probe. Traces were filtered between 1 and $500 \mathrm{~Hz}$; R1 and R2 are different subjects. Gamma-band LFP oscillations occurred in distinct events, which were detected using a thresholding procedure; example low-gamma events are shaded in blue, high-gamma events in green. Note that the gamma amplitude increases from the DM to VL sites. (Figure legend continues.) 
A

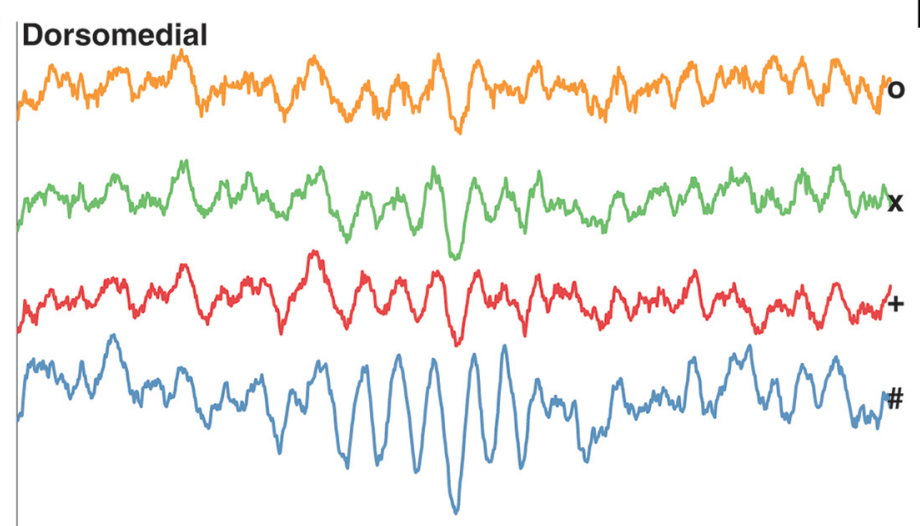

Ventrolateral

0

C

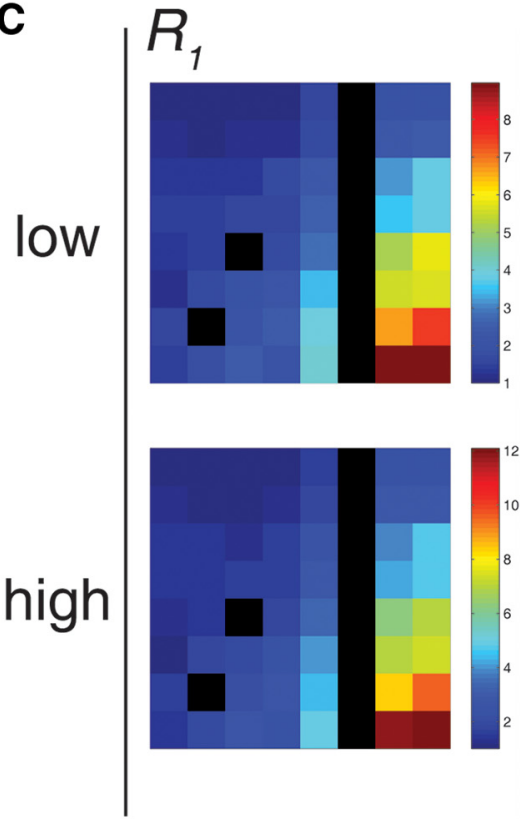

B

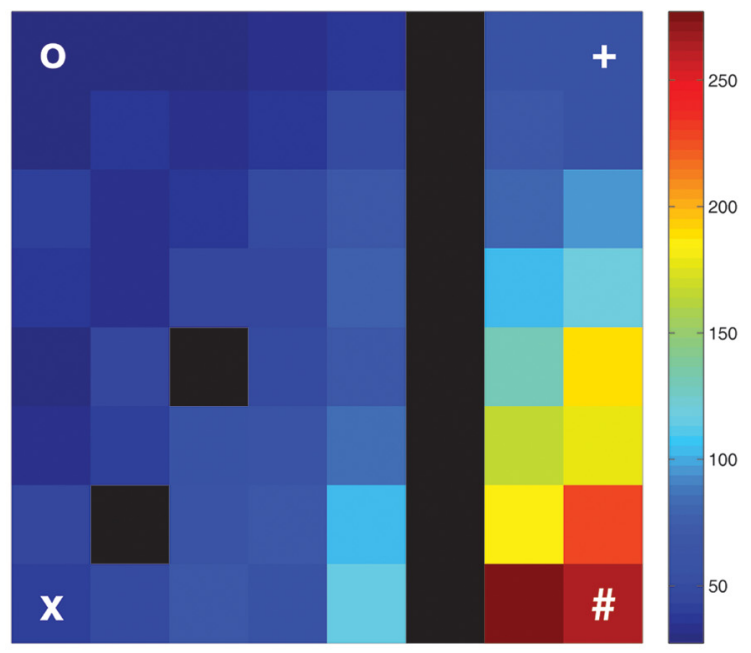

Figure 2. Gamma-band LFP oscillations in the vStr form a dorsomedial to ventrolateral power gradient. $A$, Raw LFP traces from the recording electrodes at the dorsomedial ( 0 ), ventromedial (x), dorsolateral $(*)$, and ventrolateral (\#) points of the silicon probe for a representative low-gamma event. Gray bar spans the length of the gamma event (see Materials and Methods for details of gamma detection). $\boldsymbol{B}$, Heat map showing gamma power $\left(\mu \mathrm{V}^{2}\right)$ across the recording array ( 64 sites, regularly spaced in an $8 \times 8$ grid spanning $1.4 \mathrm{~mm}^{2}$; see Fig. $1 B$ for probe layout) during the same low-gamma event as seen in the raw traces. Gamma power is approximately five times greater in the ventrolateral site compared with the dorsomedial site. C, Average low- and high-gamma power across entire recording sessions (one each for subjects R1-R4; scale is normalized to the channel with the lowest power). Black spaces represent defective recording sites (see Materials and Methods for defective site criteria).

(Fig. 3A). This systematic power gradient was further confirmed by plotting gamma power as a function of distance from the ventrolateral pole of the probe confirmed the systematic power gradient (Fig. $4 A, B$ ).

To determine whether this gradient was simply a consequence of differences in probe impedance values or other peculiarities of the recording setup, we compared the power gradient obtained

(Figure legend continued.) B, Recording locations as determined by histological processing. For silicon probes (inset) used in the LFP-mapping experiment, recording locations are indicated by the corners of the probe $(0,+, x, \#)$. Tetrodes used in the naris occlusion experiment are marked with dots. Colors correspond to different subjects. C, Dorsal view of the electrode locations to demonstrate the angle of the probes (lines) and location of tetrodes (dots). $\boldsymbol{D}$, Field pairwise phase consistency (PPC) (Vinck et al., 2011) of a representative vStr unit showing a clear peak in the gamma band. Dotted red lines indicate the SD obtained from 1000 ISI shuffles. during detected gamma oscillation events with the power gradient from a set of randomly chosen control events. By fitting a plane to the distribution of power across the probe, we could quantify how much of the variance in power across probe sites was accounted for by a linear power gradient. If this gradient was due to nonspecific properties of the signal, then this pattern would be similar during true gamma oscillations and nongamma events. Contrary to this scenario, the ventrolateral gradient was strongly attenuated for the random control events (Fig. 3B, lowgamma events mean $R^{2}=64.46 \pm 14.08$, low-gamma matched random epochs mean $R^{2}=25.19 \pm 21.83$; high-gamma events mean $=59.28 \pm 15.54$, high-gamma matched random epochs mean $=18.59 \pm 18.15$; independent samples $t$ test: $t_{(2690)}=$ 55.47, $p<0.001$ for low-gamma; $t_{(2308)}=57.86, p<0.001$ for high-gamma). Furthermore, as reported previously, high-voltage spindles displayed a power gradient in the opposite direction, 
A
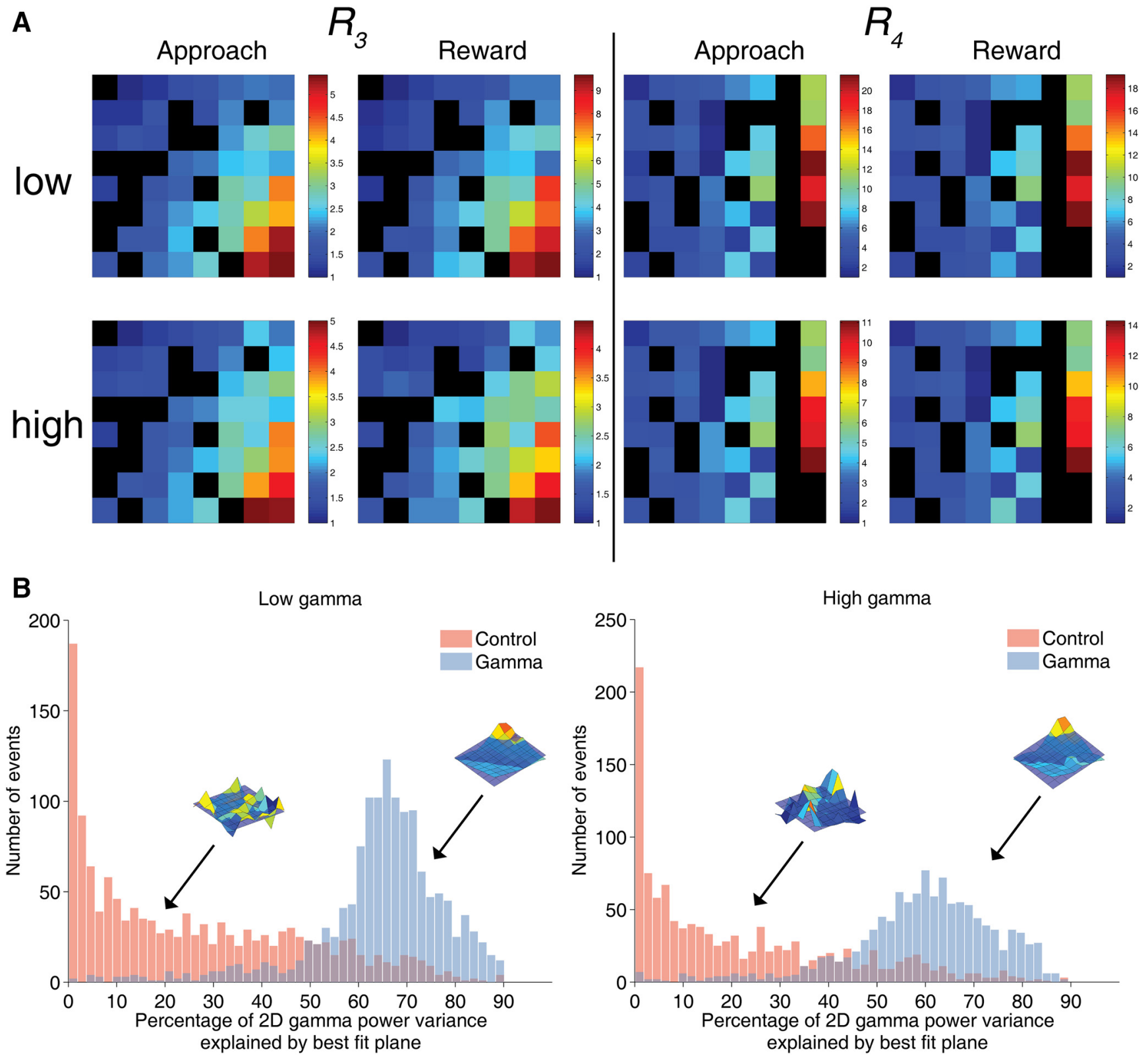

Figure 3. The dorsomedial to ventrolateral gamma power gradient in the vStr LFP is conserved across different behaviors and is significantly different from duration-matched control epochs, which had low power in both gamma bands (see Materials and Methods for details). $A$, Average gamma power distributions across vStr during active foraging and reward consumption for two subjects that completed the foraging task. $\boldsymbol{B}$, Histograms of variance explained $\left(R^{2}\right)$ for plane fits to low-gamma (left) and high-gamma (right) and control events of equivalent length (red). Gamma events are generally well fit by a plane (high $R^{2}$ values), whereas control events were less well fit. Insets show representative gamma and control events.

with largest power at the dorsomedial pole (Fig. $4 C$, inset; Berke et al., 2004). Therefore, the ventrolateral power gradient observed during gamma oscillations does not result from nonspecific probe or recording system properties.

The ventrolateral gamma power gradient identified above suggests the lack of a local source (in the vStr) for these oscillations. To determine the source of vStr gamma, we first plotted phase differences relative to the ventrolateral recording site. Although the specific pattern of these phase/temporal differences varied across subjects, these differences were consistently small $\left(<15^{\circ}\right.$; Fig. $\left.5 A, B\right)$; in particular, there was no evidence of phase reversals, a tell-tale sign of systematically arranged sink/source pairs. The patterns of phase differences were consistent between low- and high-gamma within subjects. Next, we applied CSD analysis, which, in accordance with the near-zero phase gradi- ents, showed only very small sink/source pairs in both single examples (Fig. 6A,B) and when averaged across all events (Fig. $6 C)$. Therefore, it appears that no obvious source of either low- or high-gamma oscillations exists within the vStr.

\section{Experiment 2: Unilateral naris occlusion strongly reduces vStr gamma power}

The clear gradient in vStr gamma power and the lack of phase reversals are consistent with Berke's (2009) proposal that the adjacent piriform cortex, known to generate strong gamma oscillations, may be the main source of vStr LFP gamma. Given that piriform gamma is known to be abolished by occlusion of the ipsilateral nostril (Zibrowski and Vanderwolf, 1997), we tested the effects of ipsilateral naris occlusions on vStr gamma power by inserting removable nose plugs (see Materials and Methods). 
A

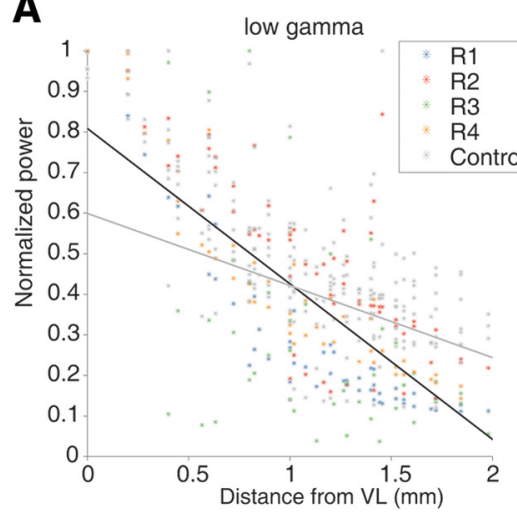

B

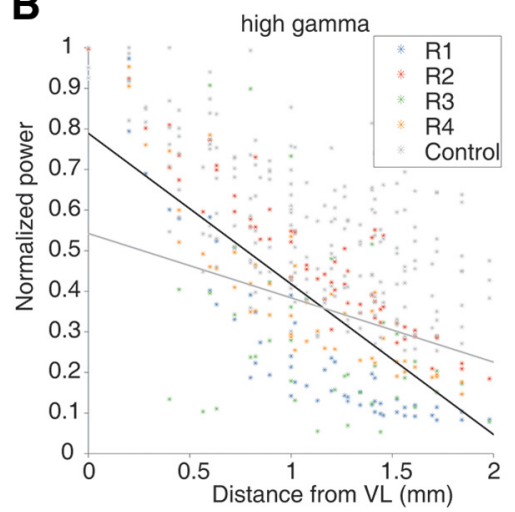

C

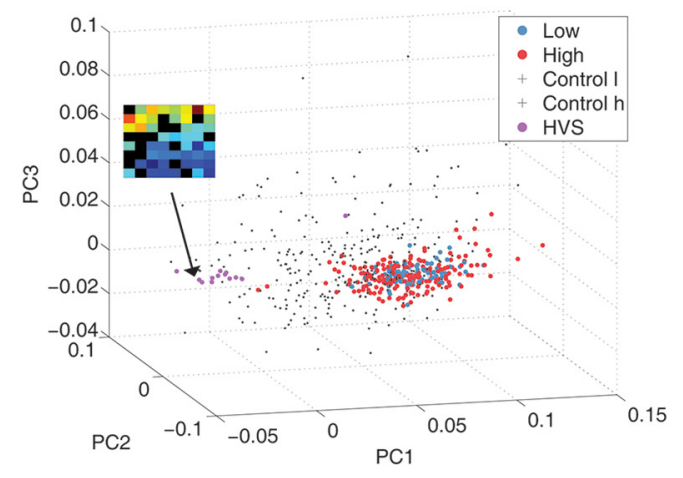

Figure 4. Gamma events form a consistent dorsomedial to ventrolateral power gradient that can be separated from high voltage spindles and control epochs. $\boldsymbol{A}, \boldsymbol{B}, \mathrm{Gamma}$ power plotted against distance from the most ventrolateral site on the probe for low-gamma $(\boldsymbol{A})$ and high-gamma $(\boldsymbol{B})$ bands. Each point indicates data from a single recording site in a single recording session; different colors indicate subjects; control epochs are shown in gray. Best-fit lines are shown for low-/high-gamma events in black and control epochs in gray. $\boldsymbol{C}$, Principal component analysis (PCA) on the power gradients across events (points) reveals that the power gradients for low-gamma and high-gamma are indistinguishable from each other, yet are clearly separate from control epochs and high-voltage spindles.
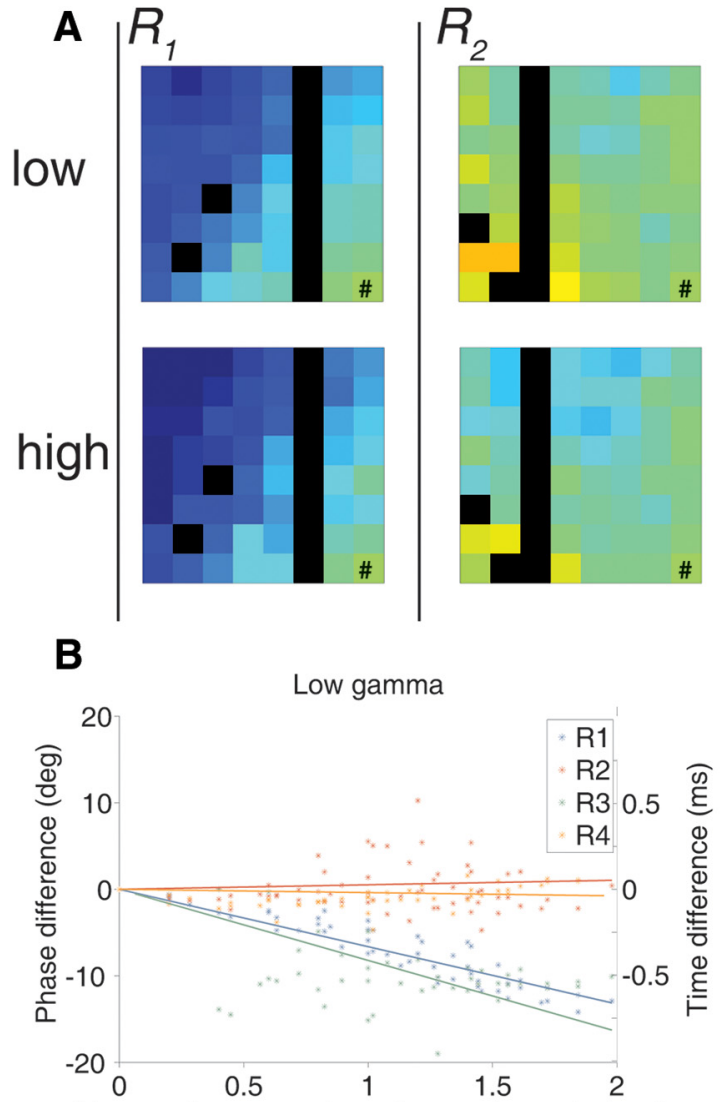

Distance from ventrolateral most electrode $(\mathrm{mm})$

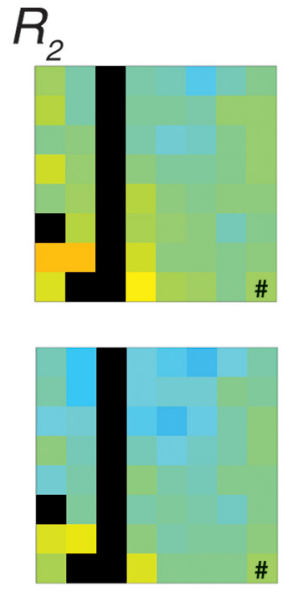

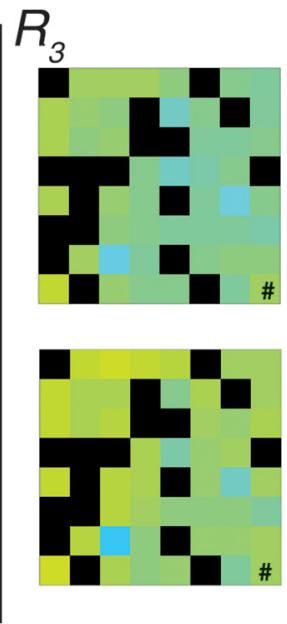

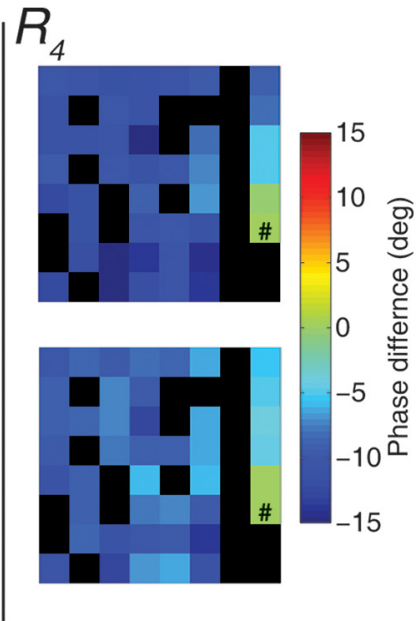

High gamma

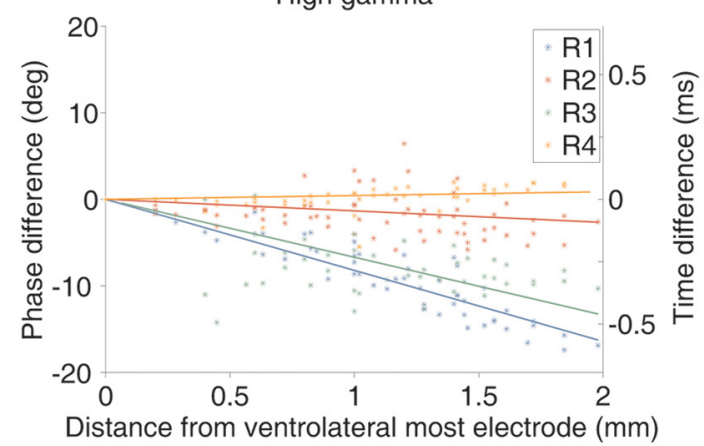

Figure 5. Phase differences between gamma oscillations recorded across the vStr are small. $A$, Average phase differences (in degrees) relative to the most ventrolateral electrode (\#). Phase differences were consistently near zero in two subjects (R2 and R3) or exhibited a systematic phase lag that increased with distance from the ventrolateral pole (R1 and R4); however, even in the latter case, maximum phase lags were small $\left(<15^{\circ}\right)$. Phase differences were computed across the center three cycles of each gamma event; negative phase differences indicate lag relative to the ventrolateral reference site. $\boldsymbol{B}$, Same data as in $\boldsymbol{A}$, but showing phase differences (in degrees) and temporal lag (in milliseconds) as a function of distance to the ventrolateral reference electrode (\# above). Temporal lags were computed from the phase differences using the average period for each gamma band of interest ( $55 \mathrm{~Hz}$ for low-gamma, and $80 \mathrm{~Hz}$ for high-gamma).

Contralateral occlusions performed alternately before or after the ipsilateral condition provided a control for nonspecific (e.g., behavioral) effects of naris blockage (Fig. 7A). Ipsilateral naris occlusions effectively abolished low- and high-gamma power relative to the contralateral condition, and relative to the unoccluded conditions before or after (pre or post, respectively;
Fig. 7B). Although power spectral densities of individual recording sessions varied, likely due to behavioral differences, gamma suppression was highly consistent across sessions and subjects (Fig. 7C-E).

To quantify this effect, we compared gamma power extracted from the power spectral density during ipsilateral and contralat- 

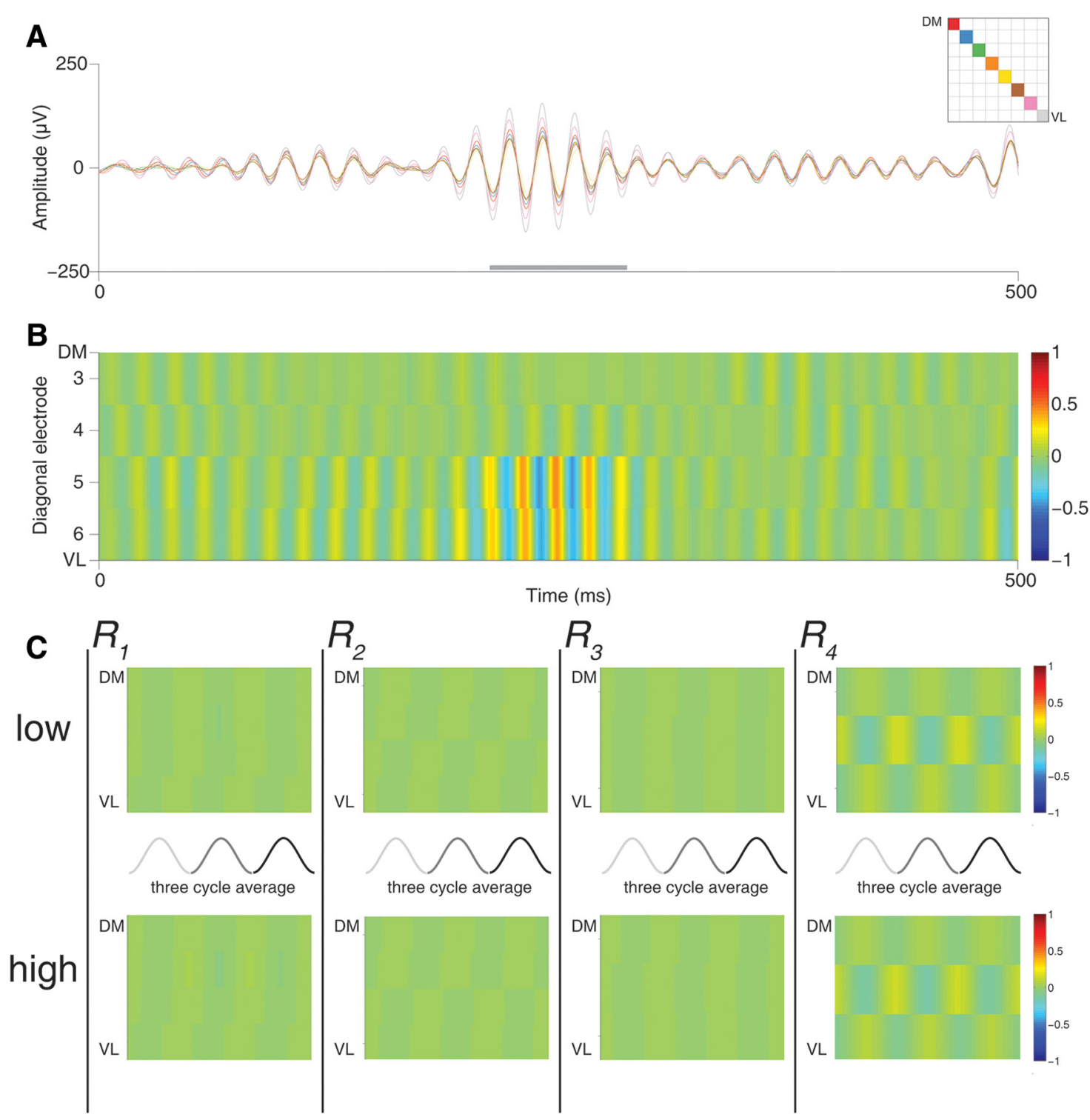

Figure 6. CSD analysis of gamma events. A, Filtered low-gamma event (same as shown in Fig. 2A). Each trace represents a recording site on the diagonal of the silicon probe (inset). Note the change in power along the dorsomedial to ventrolateral axis but very similar phases. $B$, Sample CSD over the same low-gamma event. Pseudocolor scale represents fractional values relative to a $180^{\circ}$ phase inversion (source/sink pair). Only a weak source/sink appears on the ventrolateral pole across electrodes, corresponding to the slight phase shift in the example traces. C, Average CSD across the center three cycles (gray lines) by subject event. Note that no clear source/sink pair emerges, consistent with the lack of a phase reversal in the gamma-band LFP.

eral occlusions after normalizing to gamma power during nonoccluded control conditions (pre and post recording epochs). Only ipsilateral occlusion significantly reduced gamma power in both low- and high-gamma bands to a mean of $0.48 \pm 0.05$ (SEM) and $0.62 \pm 0.04$ of the control condition, respectively (Fig. $7 F, G)$. Paired $t$ tests confirmed that the reduction was indeed significant for both the low-gamma $\left(t_{(11)}=-10.64, p<0.001\right)$ and high-gamma $\left(t_{(11)}=-5.10, p<0.001\right)$ bands relative to the power during the contralateral occlusion. The contralateral occlusion failed to reduce low-gamma power compared with the control $\left(1.00 \pm 0.06\right.$ of the control condition, $t_{(11)}=0.02, p=$ $0.99)$. Although contralateral occlusion produced a small decrease in the high-gamma power relative to the control $(0.87 \pm$ 0.05 of the control condition, $t_{(11)}=-2.66, p=0.02$ ), ipsilateral occlusion provided a significantly greater reduction in gamma power compared with contralateral occlusion for both the lowgamma $\left(t_{(11)}=-11.62, p<0.001\right)$ and high-gamma $\left(t_{(11)}=\right.$ $-10.79, p<0.001)$ bands.
This strong reduction in gamma power could be due to fewer gamma events occurring and/or events having lower gamma power. Gamma event detection applied to the occlusion conditions yielded a significantly lower number of gamma events in the ipsilateral occlusion recording (pre and post session event count normalized to 1 ; low-gamma events, $0.04 \pm 0.21$; high-gamma: $0.13 \pm 0.03)$ compared with the contralateral occlusion recording (low-gamma: $1.09 \pm 0.19$, paired $t$ test $t_{(11)}=-5.73, p<$ 0.001; high-gamma: $0.77 \pm 0.17, t_{(11)}=-4.10, p<0.005$ (Fig. $7 H)$. The number of events in the ipsilateral occlusion was significantly lower than number of detected events in the unoccluded condition for the low-gamma $\left(t_{(11)}=-44.93, p<0.001\right)$ and high-gamma $\left(t_{(11)}=-29.59, p<0.001\right)$ bands. The contralateral occlusion did not differ compared with the control for low-gamma events $\left(t_{(11)}=0.47, p=0.69\right)$ or high-gamma events $\left(t_{(11)}=-1.41, p=0.19\right)$. Further supporting the robustness of this result, the ipsilateral condition gamma power and gamma event count was lower than the contralateral condition gamma 
A

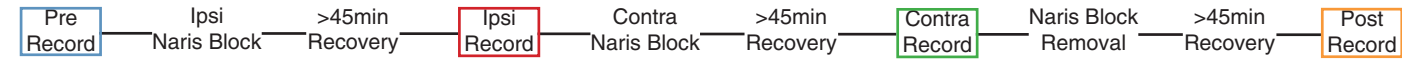
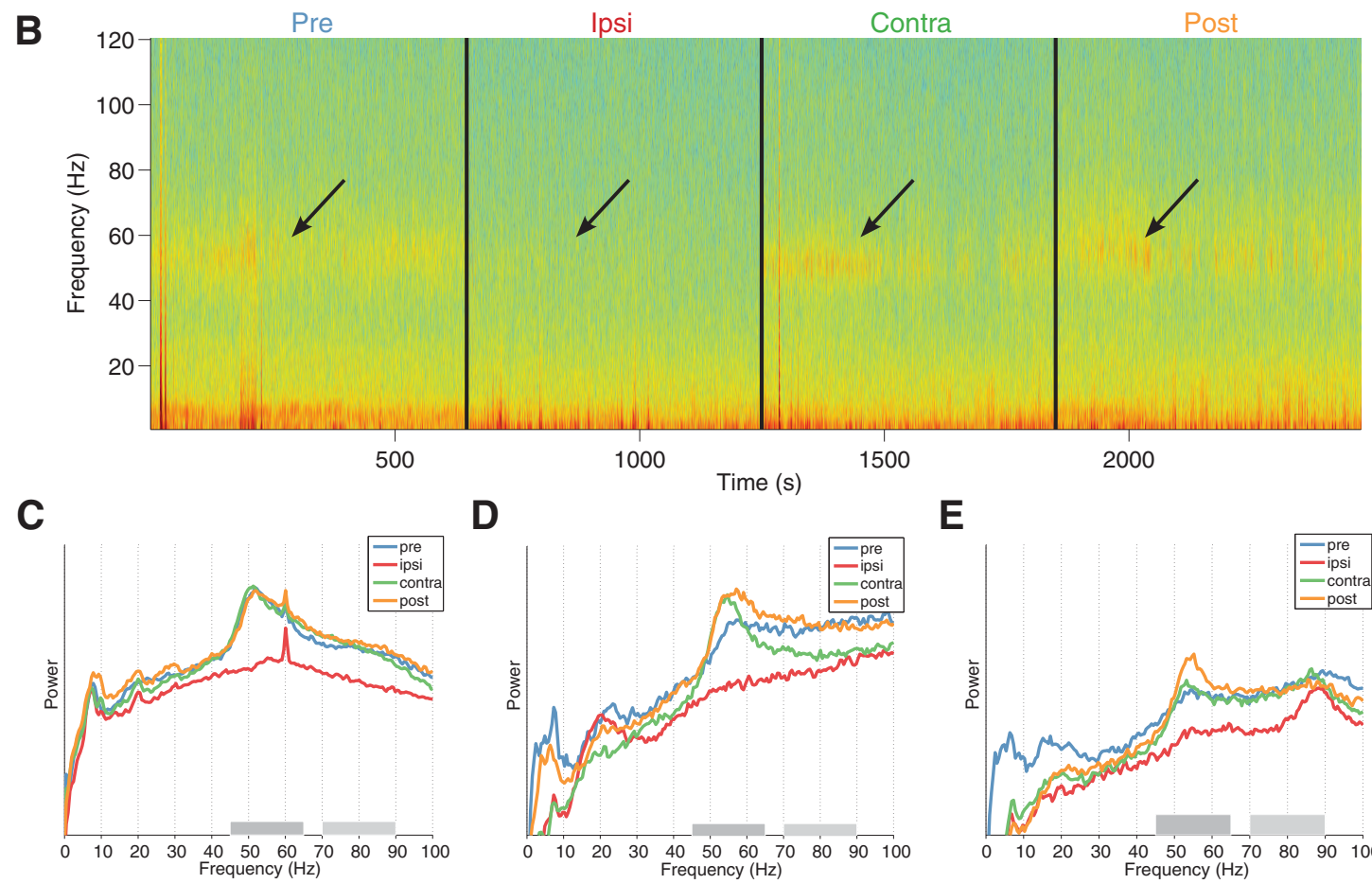

$\mathbf{F}$

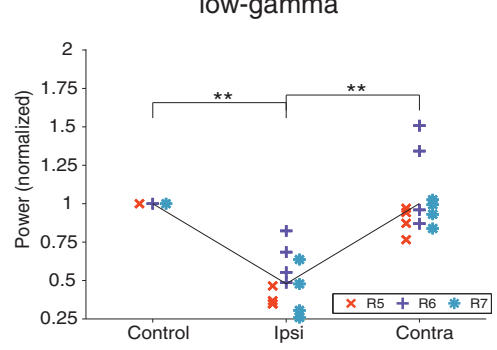

D

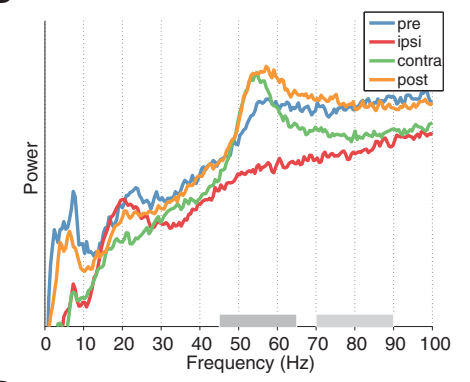

G

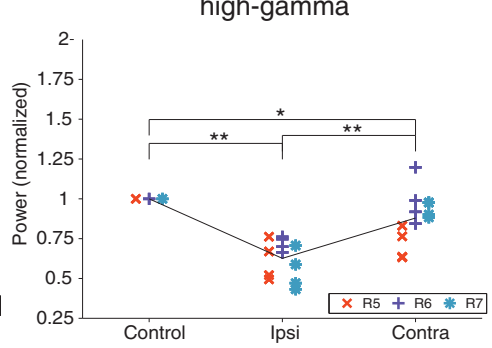

E

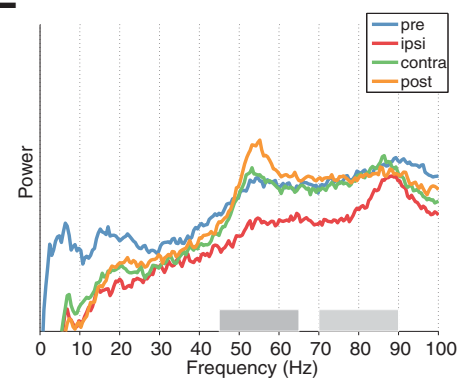

H

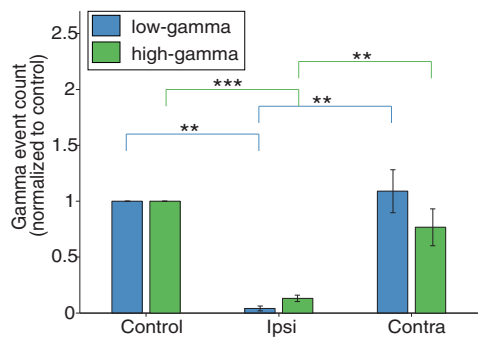

Figure 7. Ipsilateral, but not contralateral, naris occlusion reduces gamma power and event occurrence in the ventral striatum. $A$, Naris experiment timeline. Ipsilateral and contralateral occlusion order was counterbalanced across days. $\boldsymbol{B}$, Spectrogram across experimental conditions in a single session. Arrows indicate decrease in gamma-band power during ipsilateral naris occlusion. $\boldsymbol{C}-\boldsymbol{E}$, Normalized PSDs of representative sessions from each subject ( $R 5, \mathrm{R} 6$, and $\mathrm{R} 7$, respectively). Each session shows a clear reduction in gamma-band power for the ipsilateral occlusion condition only (red line). Note that, although PSDs differed between sessions (e.g., high-voltage spindles, $7-11 \mathrm{~Hz}$, in the post condition in $\mathbf{D}$ ), the reduction in gamma power was highly consistent. PSDs were computed on the first derivative of the data to remove the $1 / f$ trend. $F, G$, Comparison of the average power in each session/subject (R4-R7) within the low-gamma/high-gamma band. Ipsilateral and contralateral conditions were normalized to the unoccluded condition. $\boldsymbol{H}$, Comparison of the average number of detected gamma events per condition normalized to the unoccluded condition (average between pre and post). The ipsilateral condition yielded significantly fewer events for the same recording duration (see main text). Error bars indicate SEM.

power in every individual session without exception. Therefore, ipsilateral naris occlusion resulted in a strong reduction in both gamma power and the number of events detected.

\section{Discussion}

We have demonstrated that the power of gamma oscillations in the vStr LFP increases along a clear dorsomedial-to-ventrolateral gradient; that the phases of gamma oscillations across the vStr are highly consistent, with no evidence of reversals indicating a local sink/source pair; and that gamma oscillations are strongly reduced by occlusion of the ipsilateral, but not contralateral, nostril. Together, these results strongly suggest that gamma oscillations in the vStr LFP are volume conducted from piriform cortex, consistent with initial observations by Berke (2009), who reported highly similar LFPs in vStr and piriform cortex. Here, we build on this initial work by providing systematic coverage of the vStr with high-density silicon probes, separately analyzing low- and high-gamma bands and different behaviors and providing a causal manipulation known to disrupt piriform gamma oscillations.

What are the possible scenarios for the source(s) of gamma oscillations in the vStr LFP? We considered several nonexclusive contributions. Volume conduction (Fig. 8A) predicts a linear power gradient and a lack of phase reversals across the vStr, consistent with our results. This lack of phase reversals is inconsistent with de novo local generation of gamma oscillations in the LFP (Fig. $8 B$ ), as could be supported by cortical pyramidal-interneuron circuits demonstrated in neocortical areas (Cardin et al., 2009; Sohal et al., 2009; Siegle et al., 2014) or by cell-intrinsic oscillations (Taverna et al., 2007). A different possibility is that LFP oscillations result from local transmembrane currents, but are inherited from inputs to the vStr through the synaptic currents that they generate (Fig. $8 \mathrm{C}$ ); a more subtle version of the 
A

\section{volume conduction (piriform source)}

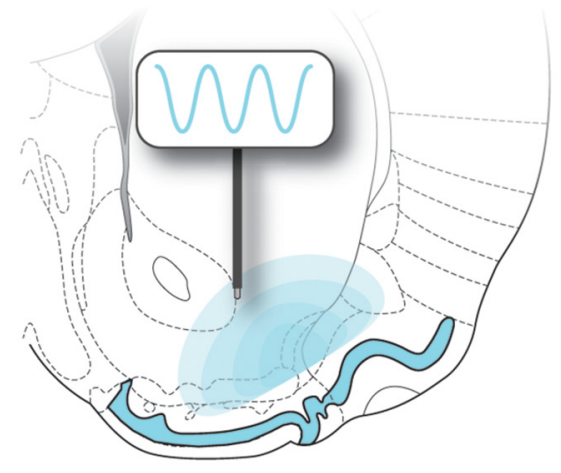

C

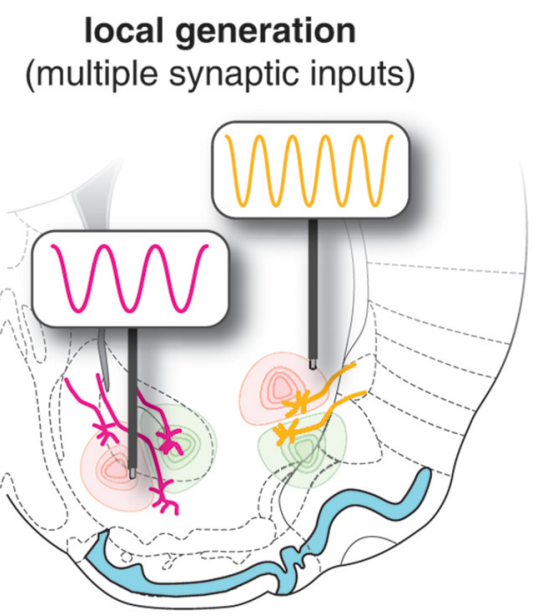

B

$$
\begin{aligned}
& \text { local generation } \\
& \text { (cell-intrinsic, circuit) }
\end{aligned}
$$

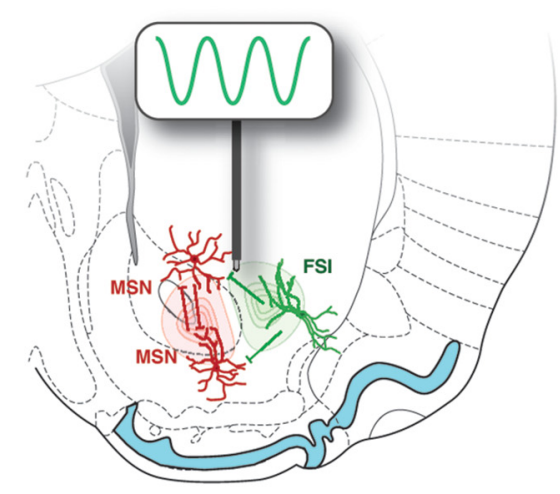

D

$$
\begin{aligned}
& \text { local generation } \\
& \text { (synaptic inputs from piriform) }
\end{aligned}
$$

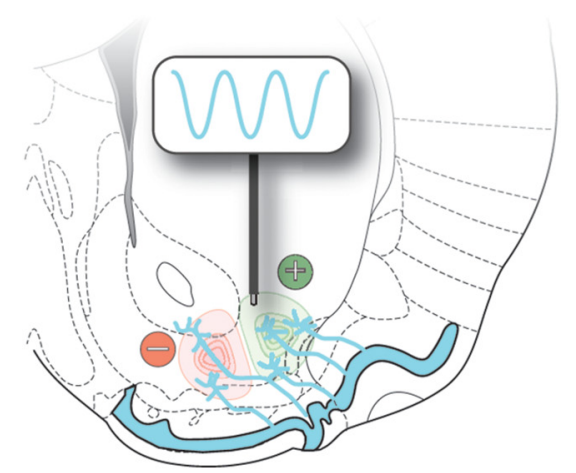

Figure 8. Four possible scenarios for the generation of gamma-band oscillations in the vStr. $\boldsymbol{A}$, Volume conduction originating from the adjacent piriform cortex would show no clear phase reversals within the vStr and a linear power gradient (blue shaded area). $\boldsymbol{B}$, Local mechanisms such as cell-intrinsic currents and excitatory-inhibitory (red and green, respectively) circuitry produce local gamma oscillations de novo in vStr. C, Local sources arising from synaptic currents inherited from rhythmic inputs to the vStr (here idealized as two different afferent sources, orange and magenta potentially associated with different gamma frequencies). $\boldsymbol{D}$, Highly specific version of the same idea, in which rhythmic inputs from the adjacent piriform cortex, the density of which falls off with distance from the piriform, generate synaptic transmembrane currents in the vStr. As discussed in the main text, our results suggest the account A, volume conduction, is the dominant contributor to gamma oscillations in the vStr.

same idea is a gradient of inputs from piriform cortex organized such that the density of inputs decreases with distance (Fig. 8D). However, a challenge faced by these inheritance accounts is that the distribution of gamma power across the vStr does not appear to match known distributions of anatomical inputs (Groenewegen et al., 1999; Humphries and Prescott, 2010). In addition, the lack of a clear layered organization in the striatum provides a further challenge for any account relying on local generation, as we discuss next. Therefore, our results appear most consistent with the volume conduction scenario (Fig. 8A).

The biophysics of LFP generation generally require sink/ source pairs of transmembrane currents to be aligned so that their contributions may sum spatially to generate systematic changes in the LFP (Nunez and Srinivasan, 2006; Buzsáki and Wang, 2012). The striatum, as a nonlayered structure with approximately radially symmetric dendritic arbors (Kawaguchi et al., 1995; Tepper et al., 2004, 2010), lacks the organization conducive to spatial summing of currents. Nevertheless, there have been reports of local heterogeneity in vStr gamma oscillations. For instance, Kalenscher et al. (2010) and Morra et al. (2012) show example recordings for which specific channels show phases or amplitudes apparently inconsistent with volume conduction. When we found such examples in our data, however, they could be attributed to impedance magnitude or angle changes on isolated electrode sites; the high-density view afforded by Si probe recordings can disambiguate these cases. A different body of work has suggested that high-frequency oscillations can be generated locally in the vStr because they are affected by infusions of MK801 and lidocaine into the vStr (Hunt et al., 2010; Olszewski et al., 2013); however, given its anatomical proximity, it is conceivable that some of the drugs spread to act on the piriform cortex.

It is notable that, although the phase differences that we observed across the vStr were consistently small, there was some evidence for systematic deviations from zero in the form of increasing phase delay with distance (Fig. 5). Volume conduction with nonzero phase delays could result from a medium that is not purely resistive, but also has capacitance. Whether brain tissue has significant capacitance is a matter of some controversy; studies in monkeys have tended to report support for purely resistive 
conditions (Logothetis et al., 2007; Kajikawa and Schroeder, 2011; for discussion, see Kajikawa and Schroeder, 2015), whereas modeling work and, to our knowledge, a single rat study have suggested appreciable capacitance (Bédard et al., 2004, 2010).

A different possibility is suggested by Sirota et al. (2008), who observed a linearly increasing phase delay with distance for the volume conduction of the hippocampally generated theta rhythm into the overlying cortex (see their Fig. 8A4). They hypothesized that such a pattern could result from interference between multiple phase-shifted theta sources within the hippocampus. By analogy, multiple gamma generators embedded within the distinctive folded shape of the piriform cortex could result in interference patterns that, depending on the alignment of the probe, may manifest as phase delays. Given this possibility and further variables that can contribute to the conduction speed and spatial reach of the LFP (Lindén et al., 2011; Zhang et al., 2014), we suggest that our phase data are consistent with volume conduction. In any case, a key observation is that we found no evidence of phase reversals or local power inhomogeneities in vStr LFP gamma.

Given the above interpretation of gamma oscillations in the vStr LFP as volume-conducted from the piriform cortex, what are we to make of the well established spike-field phase locking of vStr neurons in the gamma band (Berke et al., 2004; van der Meer and Redish, 2009; Kalenscher et al., 2010; Howe et al., 2011)? One obvious potential explanation is that this relationship occurs through direct synaptic inputs from piriform cortex (Brog et al., 1993; Schwabe et al., 2004), which could account for phase locking in the vStr: to the extent that piriform cortex inputs are effective in driving vStr spiking, then that spiking would be expected to lock to the field potential originating from the same source structure. This account implies that, depending on the effectiveness of the piriform input in shaping vStr activity, the vStr spikefield relationship may be strong or entirely absent; for instance, vStr spiking may be beautifully rhythmic but unrelated to the LFP or, conversely, the LFP may be beautifully rhythmic but vStr spiking may be irregular. Such a variable relationship would also be consistent with dissociations in task variable coding between vStr spiking and the LFP, such as that observed by Malhotra et al. (2015).

Establishing the source of gamma oscillations in the vStr LFP is important for at least two distinct reasons. First, knowledge of the source directly informs the interpretation of recorded signals. Because vStr neurons can phase lock to gamma oscillations in the LFP (Berke, 2009; Kalenscher et al., 2010; van der Meer et al., 2010; Howe et al., 2011; Dejean et al., 2017) and vStr ensemble spiking can predict LFP gamma oscillation frequency (Catanese et al., 2016), the vStr LFP clearly contains at least some information about local (spiking) activity. However, if vStr LFPs contain a component volume conducted from the piriform cortex, as we have shown, then some changes in the LFP may reflect processing in piriform cortex rather than local processing in vStr.

The second reason that it is important to identify the source(s) of the vStr LFP relates to how that signal is controlled. Several studies have linked properties of the vStr LFP to different task components such as reward approach, receipt, and feedback processing (Cohen et al., 2009b; van der Meer and Redish, 2009); to trait-level variables such as impulsivity (Donnelly et al., 2014); and to translationally relevant interventions such as manipulations of the dopamine system (Berke, 2009; Lemaire et al., 2012; Morra et al., 2012). Such associations suggest that causing changes to the vStr LFP may be a therapeutic goal for deep brain stimulation studies (McCracken and Grace, 2009; Doucette et al.,
2015). Our results imply that, to change the vStr LFP either endogenously or using experimental manipulations, it may paradoxically be more effective to target piriform cortex rather than the vStr itself. Similarly, a long-standing notion is that vStr may provide a "switchboard" between inputs from prefrontal cortex, amygdala, and hippocampus (O'Donnell and Grace, 1995; Gruber et al., 2009). Rhythmic fluctuations in activity levels and their temporal coordination within and between brain areas have been suggested to contribute to such switching functions (Fries, 2005, 2015). At least in some cases, these excitability fluctuations are reflected in the LFP (Cardin et al., 2009). Although vStr circuitry may contribute to gamma oscillations in local excitability (e.g., through intrinstic oscillations in FSIs; Taverna et al., 2007), this is unlikely to be the only factor given the clear phase locking of FSIs to the LFP, which in turn appears to derive from piriform cortex. Therefore, our results suggest that local vStr circuitry is unlikely to be in full control of the timing and frequency of its own gamma oscillations in excitability or population spiking activity.

More generally, gamma oscillations volume conducted and/or inherited from a common piriform source may be a powerful synchronizing drive of neural activity in the rodent limbic system. For instance, LFP synchrony in the gamma band across limbic structures such as prefrontal cortex, orbitofrontal cortex, ventral hippocampus, and amygdala (van Wingerden et al., 2014; Harris and Gordon, 2015; Catanese et al., 2016) may, at least in rodents, be shaped by piriform input. Given the much larger distance from the human vStr to piriform cortex and the widespread use of relatively local referencing in depth electrode recordings, it seems a priori unlikely that gamma oscillations in the human vStr are volume conducted from piriform cortex. Intriguingly, however, there is at least some evidence that lateralized nasal breathing affects both the EEG signal and various aspects of cognitive performance (Block et al., 1989; Zelano et al., 2016); intracranial EEG recordings in epilepsy patients show a connection between nasal breathing and increases in power of human delta $(0.5-4 \mathrm{~Hz})$, theta $(4-8 \mathrm{~Hz})$, and beta $(13-34 \mathrm{~Hz})$ oscillations in the piriform, amygdala, and hippocampus. Although gamma activity has been linked to respiration in the olfactory circuit in rodents (Gault and Leaton, 1963), the time course of vStr gamma power rules out respiration as the only factor controlling gamma oscillations in the vStr LFP. For instance, several studies have noted strong suppression of gamma power as animals run compared with when they rest (van der Meer and Redish, 2009; Malhotra et al., 2015).

Our study has a number of limitations: we chose to focus on gamma-band oscillations for several reasons, including the high consistency with which these oscillations can be probed across multiple species (rodents and humans in particular), because it is the vStr oscillation band that has received the most attention in terms of behavioral correlates and relationship to spiking activity, and because gamma oscillations are plentiful during rest and during behavior. However, clearly, it would be of interest to determine the sources of other oscillations in the vStr LFP, such as delta, theta, and beta, which have all been linked to local spiking activity and behavior (van der Meer and Redish, 2011; Howe et al., 2011; Stenner et al., 2015; Malhotra et al., 2015). The data that we recorded as part of this study did not reliably contain clearly identifiable epochs with these oscillations, so this is an avenue for further work. In addition, our naris occlusion procedure likely affects olfactory areas in addition to piriform cortex, such as the olfactory bulb and the olfactory tubercle (in rats: Zibrowski and Vanderwolf, 1997); however, because of its large size, convoluted shape, and positioning at the ventral surface of the brain, 
piriform cortex is difficult to target with higher specificity. Centrifugal afferents from the entorhinal and piriform cortices and olfactory tubercle are capable of modulating olfactory bulb gamma even in the absence of the main peduncle input (Gray and Skinner, 1988), yet our manipulation results in a strong suppression of gamma power, suggesting that the entire circuit is sufficiently impaired. Despite this limitation, we point to the convergence between the naris occlusion experiment and the power gradient observed in the probe recordings to support the most parsimonious interpretation that gamma LFP oscillations in the vStr originate in piriform cortex.

In closing, we stress an important point: the conclusion that vStr gamma LFP oscillations are volume-conducted from piriform cortex does not mean that oscillations in the vStr LFP are not important or are an epiphenomenon. As pointed out earlier, the spiking of vStr neurons shows clear oscillatory signatures, including cell-intrinsic oscillations in the gamma range (Taverna et al., 2007). Indeed, given that multiple inputs to the vStr are known to have oscillatory activity at the LFP and spiking levels, it would be hard to imagine how vStr activity would not itself also show oscillations. In turn, these oscillations can be used as an access point to define and manipulate specific functional subpopulations and state changes, as has been tremendously successful in other areas (Pesaran et al., 2002; Colgin et al., 2009; Bosman et al., 2012). A crucial distinction to make is between oscillations in the LFP and oscillations in local neural excitability and spiking. Our results show that, in vStr, this link is indirect, motivating care in the interpretation of the vStr LFP and suggesting future work in determining how olfactory inputs may shape rhythmic coordination, not just in the vStr, but in other limbic structures as well.

\section{References}

Akam T, Kullmann DM (2010) Oscillations and filtering networks support flexible routing of information. Neuron 67:308-320. CrossRef Medline

Amadei EA, Johnson ZV, Jun Kwon Y, Shpiner AC, Saravanan V, Mays WD, Ryan SJ, Walum H, Rainnie DG, Young LJ, Liu RC (2017) Dynamic corticostriatal activity biases social bonding in monogamous female prairie voles. Nature 546:297-301. CrossRef Medline

Axmacher N, Cohen MX, Fell J, Haupt S, Dümpelmann M, Elger CE, Schlaepfer TE, Lenartz D, Sturm V, Ranganath C (2010) Intracranial EEG correlates of expectancy and memory formation in the human hippocampus and nucleus accumbens. Neuron 65:541-549. CrossRef Medline

Bédard C, Kröger H, Destexhe A (2004) Modeling extracellular field potentials and the frequency-filtering properties of extracellular space. Biophys J 86:1829-1842. CrossRef Medline

Bédard C, Rodrigues S, Roy N, Contreras D, Destexhe A (2010) Evidence for frequency-dependent extracellular impedance from the transfer function between extracellular and intracellular potentials. J Comput Neurosci 29:389-403. CrossRef Medline

Berke JD (2004) Participation of striatal neurons in large-scale oscillatory networks. In: The basal ganglia VIII (Bolam JP, Ingham CA, Magill JP, eds.), pp 25-36. Boston: Kluwer Academic.

Berke JD (2009) Fast oscillations in cortical-striatal networks switch frequency following rewarding events and stimulant drugs. Eur J Neurosci 30:848-859. CrossRef Medline

Berke JD, Okatan M, Skurski J, Eichenbaum HB (2004) Oscillatory entrainment of striatal neurons in freely moving rats. Neuron 43:883-896. CrossRef Medline

Block RA, Arnott DP, Quigley B, Lynch WC (1989) Unilateral nostril breathing influences lateralized cognitive performance. Brain Cogn 9:181-190. CrossRef Medline

Bosman CA, Schoffelen JM, Brunet N, Oostenveld R, Bastos AM, Womelsdorf T, Rubehn B, Stieglitz T, De Weerd P, Fries P (2012) Attentional stimulus selection through selective synchronization between monkey visual areas. Neuron 75:875-888. CrossRef Medline

Brog JS, Salyapongse A, Deutch AY, Zahm DS (1993) The patterns of afferent innervation of the core and shell in the accumbens part of the rat ventral striatum: Immunohistochemical detection of retrogradely transported fluoro-gold. J Comp Neurol 338:255-278. CrossRef Medline

Buzsáki G, Wang XJ (2012) Mechanisms of gamma oscillations. Annu Rev Neurosci 35:203-225. CrossRef Medline

Cardin JA, Carlén M, Meletis K, Knoblich U, Zhang F, Deisseroth K, Tsai LH, Moore CI (2009) Driving fast-spiking cells induces gamma rhythm and controls sensory responses. Nature 459:663-667. CrossRef Medline

Catanese J, Carmichael JE, van der Meer MA (2016) Low- and high-gamma oscillations deviate in opposite directions from zero-phase synchrony in the limbic corticostriatal loop. J Neurophysiol 116:5-17. CrossRef Medline

Cohen MX, Axmacher N, Lenartz D, Elger CE, Sturm V, Schlaepfer TE (2009a) Good vibrations: cross-frequency coupling in the human nucleus accumbens during reward processing. J Cogn Neurosci 21:875889. CrossRef Medline

Cohen MX, Axmacher N, Lenartz D, Elger CE, Sturm V, Schlaepfer TE (2009b) Nuclei accumbens phase synchrony predicts decision-making reversals following negative feedback. J Neurosci 29:7591-7598. CrossRef Medline

Colgin LL, Denninger T, Fyhn M, Hafting T, Bonnevie T, Jensen O, Moser MB, Moser EI (2009) Frequency of gamma oscillations routes flow of information in the hippocampus. Nature 462:353-357. CrossRef Medline

Cummings DM, Henning HE, Brunjes PC (1997) Olfactory bulb recovery after early sensory deprivation. J Neurosci 17:7433-7440. Medline

Dejean C, Boraud T, Le Moine C (2013) Opiate dependence induces network state shifts in the limbic system. Neurobiol Dis 59:220-229. CrossRef Medline

Dejean C, Sitko M, Girardeau P, Bennabi A, Caillé S, Cador M, Boraud T, Le Moine C (2017) Memories of opiate withdrawal emotional states correlate with specific gamma oscillations in the nucleus accumbens. Neuropsychopharmacology 42:1157-1168. CrossRef Medline

Donnelly NA, Holtzman T, Rich PD, Nevado-Holgado AJ, Fernando AB, Van Dijck G, Holzhammer T, Paul O, Ruther P, Paulsen O, Robbins TW, Dalley JW (2014) Oscillatory activity in the medial prefrontal cortex and nucleus accumbens correlates with impulsivity and reward outcome. PLoS One 9:e111300. CrossRef Medline

Doucette WT, Khokhar JY, Green AI (2015) Nucleus accumbens deep brain stimulation in a rat model of binge eating. Transl Psychiatry 5:e695. CrossRef Medline

Dürschmid S, Zaehle T, Kopitzki K, Voges J, Schmitt FC, Heinze HJ, Knight RT, Hinrichs H (2013) Phase-amplitude cross-frequency coupling in the human nucleus accumbens tracks action monitoring during cognitive control. Front Hum Neurosci 7:635. CrossRef Medline

Fries P (2005) A mechanism for cognitive dynamics: neuronal communication through neuronal coherence. Trends Cogn Sci 9:474-480. CrossRef Medline

Fries P (2015) Rhythms for cognition: communication through coherence. Neuron 88:220-235. CrossRef Medline

Gault FP, Leaton RN (1963) Electrical activity of the olfactory system. Electroencephalogr Clin Neurophysiol 15:299-304. CrossRef Medline

Gmaz JM, Carmichael JE, van der Meer MA (2016) Neural coding for distinct sets of reward-predictive cues in the rat ventral striatum. Society for Neuroscience Annual Meeting, San Diego, CA. Abstract \#543.05.

Gray CM, Skinner JE (1988) Centrifugal regulation of neuronal activity in the olfactory bulb of the waking rabbit as revealed by reversible cryogenic blockade. Exp Brain Res 69:378-386. Medline

Groenewegen HJ, Wright CI, Beijer AV, Voorn P (1999) Convergence and segregation of ventral striatal inputs and outputs. Ann N Y Acad Sci 877: 49-63. CrossRef Medline

Gruber AJ, Hussain RJ, O'Donnell P (2009) The nucleus accumbens: a switchboard for goal-directed behaviors. PLoS One 4:e5062. CrossRef Medline

Haber SN (2009) Anatomy and connectivity of the reward circuit. In: Handbook of reward and decision making (Dreher JC, Tremblay L, eds), pp 3-27. San Diego: Academic.

Harris AZ, Gordon JA (2015) Long-range neural synchrony in behavior. Annu Rev Neurosci 38:171-194. CrossRef Medline

Hill DN, Mehta SB, Kleinfeld D (2011) Quality metrics to accompany spike sorting of extracellular signals. J Neurosci 31:8699-8705. CrossRef Medline

Howe MW, Atallah HE, McCool A, Gibson DJ, Graybiel AM (2011) Habit learning is associated with major shifts in frequencies of oscillatory activ- 
ity and synchronized spike firing in striatum. Proc Natl Acad Sci U S A 108:16801-16806. CrossRef Medline

Humphries MD, Prescott TJ (2010) The ventral basal ganglia, a selection mechanism at the crossroads of space, strategy, and reward. Prog Neurobiol 90:385-417. CrossRef Medline

Hunt M, Falinska M, Kasicki S (2009) Local injection of MK801 modifies oscillatory activity in the nucleus accumbens in awake rats. J Psychopharmacol 24:931-941. CrossRef Medline

Kajikawa Y, Schroeder CE (2011) How local is the local field potential? Neuron 72:847-858. CrossRef Medline

Kajikawa Y, Schroeder CE (2015) Generation of field potentials and modulation of their dynamics through volume integration of cortical activity. J Neurophysiol 113:339-351. CrossRef Medline

Kalenscher T, Lansink CS, Lankelma JV, Pennartz CM (2010) Rewardassociated gamma oscillations in ventral striatum are regionally differentiated and modulate local firing activity. J Neurophysiol 103:1658-1672. CrossRef Medline

Kawaguchi Y, Wilson CJ, Augood SJ, Emson PC (1995) Striatal interneurones: chemical, physiological and morphological characterization. Trends Neurosci 18:527-535. CrossRef Medline

Kucharski D, Hall WG (1987) New routes to early memories. Science 238: 786-788. CrossRef Medline

Lemaire N, Hernandez LF, Hu D, Kubota Y, Howe MW, Graybiel AM (2012) Effects of dopamine depletion on LFP oscillations in striatum are taskand learning-dependent and selectively reversed by L-DOPA. Proc Natl Acad Sci U S A 109:18126-18131. CrossRef Medline

Leung LS, Yim CY (1993) Rhythmic delta-frequency activities in the nucleus accumbens of anesthetized and freely moving rats. Can J Physiol Pharmacol 71:311-320. CrossRef Medline

Lindén H, Tetzlaff T, Potjans TC, Pettersen KH, Grün S, Diesmann M, Einevoll GT (2011) Modeling the spatial reach of the LFP. Neuron 72: 859-872. CrossRef Medline

Logothetis NK, Kayser C, Oeltermann A (2007) In vivo measurement of cortical impedance spectrum in monkeys: implications for signal propagation. Neuron 55:809-823. CrossRef Medline

Malhotra S, Cross RW, Zhang A, van der Meer MA (2015) Ventral striatal gamma oscillations are highly variable from trial to trial, and are dominated by behavioural state, and only weakly influenced by outcome value. Eur J Neurosci 42:2818-2832. CrossRef Medline

Masimore B, Schmitzer-Torbert NC, Kakalios J, Redish AD (2005) Transient striatal [gamma] local field potentials signal movement initiation in rats. Neuroreport 16:2021-2024. CrossRef Medline

McCracken CB, Grace AA (2009) Nucleus accumbens deep brain stimulation produces region-specific alterations in local field potential oscillations and evoked responses in vivo. J Neurosci 29:5354-5363. CrossRef Medline

Morra JT, Glick SD, Cheer JF (2012) Cannabinoid receptors mediate methamphetamine induction of high frequency gamma oscillations in the nucleus accumbens. Neuropharmacology 63:565-574. CrossRef Medline

Nunez PL, Srinivasan R (2006) Electric fields of the brain: the neurophysics of EEG, Ed 2. Oxford: OUP.

O’Donnell P, Grace AA (1995) Synaptic interactions among excitatory afferents to nucleus accumbens neurons: hippocampal gating of prefrontal cortical input. J Neurosci 15:3622-3639. Medline

Olszewski M, Piasecka J, Goda SA, Kasicki S, Hunt MJ (2013) Antipsychotic compounds differentially modulate high-frequency oscillations in the rat nucleus accumbens: a comparison of first- and second-generation drugs. Int J Neuropsychopharmacol 16:1009-1020. CrossRef Medline

Oostenveld R, Fries P, Maris E, Schoffelen JM (2011) FieldTrip: Open source software for advanced analysis of MEG, EEG, and invasive electrophysiological data. Comput Intell Neurosci 2011:156869. CrossRef Medline

Pennartz CM, Groenewegen HJ, Lopes da Silva FH (1994) The nucleus accumbens as a complex of functionally distinct neuronal ensembles: an integration of behavioural, electrophysiological, and anatomical data. Prog Neurobiol 42:719-761. CrossRef Medline

Pesaran B, Pezaris JS, Sahani M, Mitra PP, Andersen RA (2002) Temporal structure in neuronal activity during working memory in macaque parietal cortex. Nat Neurosci 5:805-811. CrossRef Medline

Schwabe K, Ebert U, Löscher W (2004) The central piriform cortex: anatomical connections and anticonvulsant effect of gaba elevation in the kindling model. Neuroscience 126:727-741. CrossRef Medline

Sesack SR, Grace AA (2010) Cortico-basal ganglia reward network: microcircuitry. Neuropsychopharmacology 35:27-47. CrossRef Medline

Siegle JH, Pritchett DL, Moore CI (2014) Gamma-range synchronization of fast-spiking interneurons can enhance detection of tactile stimuli. Nat Neurosci 17:1371-1379. CrossRef Medline

Sirota A, Montgomery S, Fujisawa S, Isomura Y, Zugaro M, Buzsáki G (2008) Entrainment of neocortical neurons and gamma oscillations by the hippocampal theta rhythm. Neuron 60:683-697. CrossRef Medline

Sohal VS, Zhang F, Yizhar O, Deisseroth K (2009) Parvalbumin neurons and gamma rhythms enhance cortical circuit performance. Nature 459: 698-702. CrossRef Medline

Stenner MP, Rutledge RB, Zaehle T, Schmitt FC, Kopitzki K, Kowski AB, Voges J, Heinze HJ, Dolan RJ (2015) No unified reward prediction error in local field potentials from the human nucleus accumbens: evidence from epilepsy patients. J Neurophysiol 114:781-792. CrossRef Medline

Sturm V, Lenartz D, Koulousakis A, Treuer H, Herholz K, Klein JC, Klosterkötter J (2003) The nucleus accumbens: a target for deep brain stimulation in obsessive-compulsive- and anxiety-disorders. J Chem Neuroanat 26:293-299. CrossRef Medline

Taverna S, Canciani B, Pennartz CM (2007) Membrane properties and synaptic connectivity of fast-spiking interneurons in rat ventral striatum. Brain Res 1152:49-56. CrossRef Medline

Tepper JM, Koós T, Wilson CJ (2004) GABAergic microcircuits in the neostriatum. Trends Neurosci 27:662-669. CrossRef Medline

Tepper JM, Tecuapetla F, Koós T, Ibáñez-Sandoval O (2010) Heterogeneity and diversity of striatal GABAergic interneurons. Front Neuroanat 4:150. CrossRef Medline

van der Meer MA, Redish AD (2009) Low and high gamma oscillations in rat ventral striatum have distinct rela- tionships to behavior, reward, and spiking activity on a learned spatial decision task. Front Integr Neurosci 3:9. CrossRef Medline

van der Meer MA, Redish AD (2011) Ventral striatum: a critical look at models of learning and evaluation. Curr Opin Neurobiol 21:387-392. CrossRef Medline

van der Meer MA, Kalenscher T, Lansink CS, Pennartz CM, Berke JD, Redish $\mathrm{AD}$ (2010) Integrating early results on ventral striatal gamma oscillations in the rat. Front Neurosci 4:300. CrossRef Medline

van Wingerden M, van der Meij R, Kalenscher T, Maris E, Pennartz CM (2014) Phase-amplitude coupling in rat orbitofrontal cortex discriminates between correct and incorrect decisions during associative learning. J Neurosci 34:493-505. CrossRef Medline

Vandecasteele M, Royer S, Belluscio M, Berényi A, Diba K, Fujisawa S, Grosmark A, Mao D, Mizuseki K, Patel J, Stark E, Sullivan D, Watson B, Buzsáki G (2012) Large-scale recording of neurons by movable silicon probes in behaving rodents. J Vis Exp 61:e3568. CrossRef Medline

Vinck M, Oostenveld R, van Wingerden M, Battaglia F, Pennartz CM (2011) An improved index of phase-synchronization for electrophysiological data in the presence of volume-conduction, noise and sample-size bias. Neuroimage 55:1548-1565. CrossRef Medline

Womelsdorf T, Valiante TA, Sahin NT, Miller KJ, Tiesinga P (2014) Dynamic circuit motifs underlying rhythmic gain control, gating and integration. Nat Neurosci 17:1031-1039. CrossRef Medline

Zelano C, Jiang H, Zhou G, Arora N, Schuele S, Rosenow J, Gottfried JA (2016) Nasal respiration entrains human limbic oscillations and modulates cognitive function. J Neurosci 36:12448-12467. CrossRef Medline

Zhang M, Ladas TP, Qiu C, Shivacharan RS, Gonzalez-Reyes LE, Durand DM (2014) Propagation of epileptiform activity can be independent of synaptic transmission, gap junctions, or diffusion and is consistent with electrical field transmission. J Neurosci 34:1409-1419. CrossRef Medline

Zibrowski EM, Vanderwolf CH (1997) Oscillatory fast wave activity in the rat pyriform cortex: relations to olfaction and behavior. Brain Res 766: 39-49. CrossRef Medline 